\title{
Carnets
}

Revue électronique d'études françaises de l'APEF

Première Série - 4 Numéro Spécial | 2012

Invasions \& Évasions

\section{Ontem e hoje: as Invasões Francesas nas páginas da imprensa periódica portuguesa}

\section{Fátima Outeirinho}

\section{OpenEdition}

1 Journals

\section{Edição electrónica}

URL: http://journals.openedition.org/carnets/7379

DOI: $10.4000 /$ carnets. 7379

ISSN: 1646-7698

\section{Editora}

APEF

Edição impressa

Data de publição: 1 Junho 2012

Paginação: $71-80$

\section{Refêrencia eletrónica}

Fátima Outeirinho, «Ontem e hoje: as Invasões Francesas nas páginas da imprensa periódica portuguesa », Carnets [Online], Première Série - 4 Numéro Spécial | 2012, posto online no dia 23 junho 2018, consultado o 19 abril 2019. URL : http://journals.openedition.org/carnets/7379; DOI : 10.4000/ carnets.7379

\section{(c) (i) (8)}

Carnets est mis à disposition selon les termes de la licence Creative Commons - Atribution - Pas d'utilisation commerciale 4.0 International. 


\title{
ONTEM E HOJE: AS INVASÕES FRANCESAS NAS PÁGINAS DA IMPRENSA PERIÓDICA PORTUGUESA
}

\author{
FÁTIMA OUTEIRINHO
}

Universidade do Porto

outeirinho@letras.up.pt

\begin{abstract}
Resumo
Inscrevendo a nossa reflexão no quadro teórico da imagologia, tratar-se-á, na presente comunicação, de eleger como corpus de análise periódicos cronologicamente situados no período das Invasões Francesas e periódicos relativos às comemorações do bicentenário das Invasões, com vista à deteção e consequente análise das imagens sobre o Outro estrangeiro. Considerando a importância do periodismo enquanto fautor de uma história da atualidade, considerando ainda o seu papel na construção e/ou difusão de representações culturais com impactos vários junto de uma instância de receção, tal abordagem do objeto textual escolhido permitirá equacionar e lançar luz no que toca às dinâmicas acionadas no campo das relações entre culturas e, no caso em apreço, das relações luso-francesas, pela reflexão em torno de atitudes relacionais diversas que poderão ir da fobia à mania.
\end{abstract}

\begin{abstract}
Considering the theoretical framework of imagology, in this present paper we will elect a corpus of periodicals chronologically situated during the Napoleonic wars and related to the bicentennial celebrations of French invasions, in order to detect and analyze the images of the foreigner Other. Considering the importance of journalism as an history of the present and also considering its role in the construction and/or dissemination of cultural representations with various impacts towards the readers, such an approach of the chosen texts enables to highlight several driven dynamics between cultures and, in this case, the Luso-French relations, through the reflection on the relational attitudes that may be ranged from phobia to mania.
\end{abstract}

Palavras-chave: Invasões Francesas, Imprensa periódica, imagologia, relações luso-francesas.

Keywords: French invasions, periodical press, imagology, Luso-French relations. 
São bem conhecidos de todos os acontecimentos ocorridos entre 1807 e 1811, relativos às Invasões Francesas e suas diferentes vagas, bem como a consequente Guerra Peninsular. Importa no entanto referir, como observa Manuel Fernando Vizela Marques Cardoso, em "Portugal nas vésperas das invasões francesas; contexto geopolítico e geoestratégico", que

A França, que pretendia disputar a hegemonia da Europa com a sua velha rival - a Inglaterra - iria utilizar uma estratégia indirecta para: - Através de uma acção política clandestina, fomentar e apoiar a independência das colónias inglesas da América do Norte;- Através do bloqueio continental, fechar os portos da Europa ao comércio marítimo inglês;- Complementarmente, conseguir o isolamento da Inglaterra, rompendo as alianças e as coligações que a mesma viesse a integrar. (Cardoso, 2010)

Como também resume José Miguel Sardica,

Portugal nunca interessou a Bonaparte como um fim em si mesmo - fosse como uma potência ameaçadora, uma potencial 'República Irmã', um corredor geoestratégico de passagem ou uma zona de ricos recursos para abastecimento. / Assim sendo, o problema português só se colocou a Napoleão como peça do plano mais vasto, divisado ainda pelo Directório e depois retomado, sucessivas vezes pelo Imperador, que consistia em isolar e vencer a Inglaterra através de um bloqueio do espaço continental ao comércio e exportações britânicas. (Sardica, 2005: 31)

É neste quadro sumariamente traçado, que a primeira invasão ocorre, provocando, num momento inicial, sentimentos contraditórios e equívocos. Se maioritariamente vinga uma reação anti-francesa, certo é que a perseguição, dos chamados afrancesados, dá também ela testemunho indirecto de simpatias sobretudo ideológicas de matriz francesa, a permitir ventos de modernidade. Em breve porém, uma dominante reação de repúdio para com o invasor manifesta-se, atitude que desencadeará uma intensa produção escrita periodística ou que com ela faz fronteira, como as folhas volantes de caráter tantas vezes panfletário, fazendo surgir um não despiciendo objeto textual em que a presença da imagem do estrangeiro é grandemente ocupada pela figura do francês.

Ora, como lembra Daniel-Henri Pageaux, "Les images, les représentations culturelles qu'un pays se fait d'un autre pays, sont filles de l'histoire » (Pageaux, $2003: 13$ ); "[...] num dado momento histórico e numa dada cultura, não é possível dizer, escrever seja o que for sobre o Outro. Os textos 'imagológicos' são textos em parte programados, alguns mesmo codificados e descodificáveis mais ou menos imediatamente pelo público leitor [...]." 
(Machado \& Pageaux, 2001: 53-54) e, considerando a importância do periodismo enquanto fautor de uma história da atualidade, considerando ainda o seu papel na construção e/ou difusão de representações culturais com impactos vários junto de uma instância de receção, a abordagem do objeto textual escolhido permitirá equacionar e lançar luz no que toca às dinâmicas acionadas no campo das relações entre culturas, no caso em apreço, das relações luso-francesas, pela reflexão em torno de atitudes relacionais diversas, num quadro teórico conceptual devedor da imagologia que permite tomar consciência de que "Our images of foreign countries, peoples and cultures mainly derive from selective value judgements (which are in turn derived from selective observation) as expressed in travel witing and in literary representations" (Beller, 2007:5).

Tratar-se-á então de, na presente comunicação, eleger como corpus de análise - que sabemos indicial - periódicos cronologicamente situados no período das Invasões Francesas e periódicos relativos às comemorações do bicentenário das Invasões, com vista à deteção e consequente análise das imagens ${ }^{1}$ sobre o Outro estrangeiro, porquanto tal corpus permitirá identificar e caracterizar presenças do período das invasões francesas, na memória coletiva portuguesa, ontem e hoje.

\section{As Invasões Francesas ontem}

José Tengarrinha, na sua História da Imprensa Periódica Portuguesa, recorda que "Até às Invasões Francesas o movimento da imprensa portuguesa de carácter noticioso e político foi [...] muito baixo. [...] Só em 1808 o nosso jornalismo entr[a] numa fase nova, abertamente política e de combate[...]." (Tengarrinha, 1989: 59-60) E observa que logo após a primeira invasão se assiste à proliferação da literatura jornalística panfletária e clandestina (idem: 60), atendendo ao carácter eminentemente opinativo da imprensa da época detratora da ação napoleónica entre nós.

Os periódicos em circulação caraterizam-se com frequência pelo anonimato, e mau grado a sua posição anti-francesa, apresentam-se como órgãos noticiosos grandemente assentes na tradução de textos jornalísticos espanhóis ou ingleses, visando a informação do leitor, mas podendo também desenvolver estratégias satíricas contra os franceses².

Concomitantemente e na linha seguida noutros espaços estrangeiros pela política imperial napoleónica de ação propagandística, existem igualmente periódicos que são

\footnotetext{
${ }^{1}$ Neste quadro, consideraremos imagem como a « [...] representação de uma realidade cultural estrangeira através da qual o indivíduo ou o grupo que a elaboram (ou que partilham ou que a propagam) revelam e traduzem o espaço ideológico no qual se situam." (Machado \& Pageaux, 2001: 51).

${ }^{2}$ Consulte-se, a este propósito, "Invasões Francesas: o esgrimir das penas e os papéis incendiários" (Correia, 2007).
} 
convertidos em órgãos dos franceses como a Gazeta de Lisboa e o Diário do Porto, meio de divulgação de proclamações várias, vade mecum para um quotidiano então alterado.

Assim, a imprensa periódica interessa-nos não apenas pelo conjunto de imagens sobre esse outro estrangeiro e pela ação que poderá ter exercido sobre os recetores da época, mas sobretudo pela cristalização de representações em torno do invasor e que, eventualmente, poderiam ser situadas num tempo longo, considerando nós a imagem [...] as the mental silhouette of the other, who appears to be determined by the characteristics of family, group, tribe, people or race." (Beller, 2007: 4) e que "Such an image rules our opinion of others and controls our behaviour towards them. Cultural discontinuities and differences [...] trigger positive or negative judgements and images. (ibidem). Atentemos pois nalgumas ocorrências a apoiar o nosso percurso de reflexão.

Como acima tivemos ocasião de lembrar, a invasão de Portugal constituiu-se como meio para atingir um fim. Percebe-se pois o lamento perplexo e desolado do Observador Português, Histórico e Político de Lisboa quando afirma:

\begin{abstract}
Depois de Portugal ter comprado tantas, e repetidas vezes a Paz dos seus Vassalos, tendo-se contido sempre nos limites da mais perfeita Neutralidade, alcançada por muitos milhões; não ofendendo a Potência alguma, antes observando uma indisputável condescendência com o Continente, sacrificando-se a Tratados menos decorosos à honra da Nação, tudo para manter, na actual crise, a integridade do seu Terreno, a liberdade do seu Comércio, e independência de suas Possessões; contudo nada foi bastante para impedir uma ambição desmarcada do Tirano da Europa [...] (1809: 7)
\end{abstract}

Napoleão Bonaparte é, neste periódico, figura com "bárbaras, e pérfidas intenções" (idem: 8), o "homem mais monstruoso" (idem: 9) de "depravados e monstruosos intentos" (ibidem); o seu representante Junot será apodado de "Vândalo Junot" (idem: 144), pois todos os que estão em solo nacional serão vistos como "Satélites do Tirano" (idem: 155)

Também o Resumo Histórico dos Sucessos Memoráveis da Restauração do Porto afina por diapasão semelhante, referindo-se a Napoleão como "parto infernal do negro abismo" (J.L.C.M., 1809: 3), e observando que

[...] metendo a saque a Europa toda sem outro motivo mais que a sua ambição sem limites, à qual sacrifica todos os Direitos, Religião, e Humanidade, pondo em prática para a execução dos seus projectos desastrados todos os meios que se the oferecem quer sejam honestos, quer justos, ou injustos, transformando-se em qual novo Proteu em Monsulmão [sic] com os Monsulmanos [sic], Judeu com os Judeus, e Cristão com 
os Cristãos; este homem [...] [Napoleão] formou o plano mais árduo, que tem visto as idades." (idem: 3-4)

Outros periódicos como a Abelha do Meio-Dia tão só escrevem cautelosamente que "No nosso Continente tudo anuncia próximos triunfos: quanto ao Norte nada podemos avançar, porque as Folhas Inglesas nada trazem de positivo, nem queremos encher estas páginas de notícias duvidosas: o certo é que os nossos negócios têm a melhor face." (Abelha do Meio-Dia, 16 de Outubro 1809)

Na recente obra $O$ Porto e as Invasões Francesas, Mário Matos e Lemos recorda uma imprensa de Lisboa que se apoia em cartas particulares e de oficiais sobre os acontecimentos a Norte, tratando-se ainda de noticiar, exaltar ou lamentar a ação portuguesa e, no que toca a uma publicação panfletária, atacar e/ou ridicularizar Napoleão, as suas campanhas e os seus generais (Matos e Lemos, 2009: 196).

Já em estudo sobre os traços deixados na memória portuguesa pelas campanhas napoleónicas e que percorre domínios como a pintura, a literatura, o discurso oral ou as comemorações, com o objectivo de definição duma tipologia da memória coletiva portuguesa, Teresa Caillaux de Almeida recorda a intensa produção panfletária em que Napoleão é aproximado à figura do anti-cristo e os franceses seres monstruosos, autores de violência, crueldade, roubo e pilhagem. Contudo, e Teresa Caillaux de Almeida sublinha-o, «À cet aspect traumatique de la mémoire s'ajoute celui de la gloire d'avoir battu l'armée, a priori invincible, de Napoléon. » (Almeida, 2007: 34)

Com efeito, no Resumo Histórico dos Sucessos Memoráveis da Restauração do Porto podemos encontrar registado: "Aos Portugueses do Século XIX, era reservado desenvolver aquele heroísmo, que caracterizou em todo o tempo os antigos Lusitanos, e em especial, naquelas Épocas, em que a Pátria quase a ponto de soçobrar foi por seu esforço gloriosamente restabelecida." (J.L.C.M. 1809: 1) Ou ainda: " [...] no ócio duma aturada paz ignorávamos, o, de que éramos capazes; mas os Franceses vieram finalmente despertarnos, e fazer-nos sair deste letargo." (idem: 4-5) Ressentimento e orgulho sucedem-se nos textos face à presença francesa violentamente imposta, possibilitando igualmente uma redescoberta identitária, ilustrando o que Machado e Pageaux referem sobre o processo que tem lugar na construção de hetero-representações: " [...] a imagem do Outro revela as relações que estabelecemos entre o mundo (espaço original e estranho) e eu próprio." (2001: 53)

Apoiando-se na investigação desenvolvida por António Pedro Vicente, Teresa Caillaux de Almeida lembra a possibilidade de uma mitificação do soldado português, atendendo a que a sua presença portuguesa nas tropas inglesas representava cerca de 
$15 \%$ do total e, com frequência, se registariam fugas dos soldados portugueses por ocasião dos ataques franceses (Almeida, 2007: 34).

\section{As Invasões Francesas hoje}

Se a imprensa periódica oitocentista se apresenta de teor predominantemente opinativo, o mesmo já não sucede por ocasião do bicentenário das invasões francesas, num jornalismo que se quer informativo sobre as comemorações que irão ocorrer um pouco por todo o país, e que se concentrarão de um modo particular ao longo de 2009. Assim, estamos face a uma imprensa noticiosa que dá conta das diferentes iniciativas ${ }^{3}$, uma imprensa regional extremamente presente a recordar a ação invasora partilhada por boa parte dos portugueses à época ${ }^{4}$, numa continuidade de representações que reitera a violência, a crueldade e a pilhagem ${ }^{5}$, agora sem vislumbre de ressentimento.

Numa preocupação de caráter evocativo, revisitando a História, encontramos um Santo Tirso Hoje, um Jornal das Caldas ${ }^{6}$ ou um Semanário Transmontano que noticiam eventos, rememoram e homenageiam os que perderam a vida e lutaram contra os invasores, divulgam factos da história nacional para que se perceba e compreenda a importância das Invasões Francesas para a História de Portugal ou para a Região do Douro ${ }^{7}$.

Também a imprensa de cobertura nacional abrirá as suas páginas ao bicentenário, nomeadamente o jornal Público. Numa iniciativa conjunta da Câmara Municipal do Porto e do jornal Público, apresenta-se em março de 2009 uma obra em quatro volumes para assinalar os 200 anos das Invasões Francesas: O Porto e as Invasões Francesas. Por essa ocasião, o Público publica um destacável de apresentação da edição. O objectivo

\footnotetext{
${ }^{3}$ V., por exemplo, a notícia do colóquio comemorativo do bicentenário e realizado em Santo Tirso numa parceria entre a Câmara Municipal de Santo Tirso e o Centro de Estudos de História Religiosa da Universidade Católica Portuguesa (http://www.santotirsohoje.com/?tag=invasoes-francesas)

${ }^{4}$ A obra Invasões Francesas 200 anos. Mitos, histórias e protagonistas (Cardoso, 2010) ilustra bem, através das várias histórias e episódios que narra, a dimensão alargada a todo o país da experiência invasora francesa.

${ }^{5} \mathrm{~V}$. "Os franceses invadiram Portugal com três invasões significativas em números e em tempo. A primeira decorre nos anos de 1807/08; a segunda 1809 e finalmente a terceira em 1810. Em toda elas ficou um rasto de violência e destruição que vai acompanhar Portugal e os portugueses até aos nossos dias." (http://www.espigueiro.pt/reportagem/b56a18e0eacdf51aa2a5306b0f533204.html)

6 V. afirmações do caldense Mário Lino na abertura de exposição sobre as Invasões Francesas: "Neste reencontro com a História estão bem patentes os horrores dos ventos da guerra, da violência e do fogo que devastou as localidades de Pombal e da Redinha. Com este avivar de memórias pretendemos também lembrar, em preito de homenagem, as largas centenas, se não mesmo milhares de civis, que morreram nesta região. [...] I "Decorridos 198 anos sobre estes episódios, estamos aqui sem quaisquer ressentimentos, num abraço à paz, apenas com o objectivo de recordar uma história da qual nem tudo o fogo levou." (http://www.jornaldascaldas.com/index.php/2009/03/12/caldense-e-comissario-de-comemoracoes-das-invasoesfrancesas-em-pombal/)

${ }^{7}$ A preocupação de divulgação histórica está bem presente na notícia dada pelo Semanário Transmontano a propósito das comemorações em Chaves:" Na apresentação do programa, o comandante do Regimento realçou 'oportunidade única' que esta iniciativa representa para divulgar factos da história nacional."

(http://www.semanariotransmontano.com/noticia.asp?idEdicao=171\&id=7289\&idSeccao=2352\&Action=noticia)
} 
sublinhado e que faz o lead do destacável será: "Lembrar a cada geração os principais passos dos que a precederam é um dos desígnios visados por esta iniciativa [...] ". (Público, 2009) Como referirá o coordenador da edição, Valente de Oliveira, "Impõe-se a cada geração lembrar os passos principais das que nos precederam. Isso permitirá entender muito do que somos e relativizar muitas das angústias actuais, por se poder ir buscar forças e inspiração ao que já fizemos para ultrapassar outras dificuldades." (idem)

Ainda no destacável, os contributos de Liliana Duarte e Ana Filipa Gaspar, apresentam uma breve resenha histórica dos acontecimentos ${ }^{8}$ : trata-se de referir a viragem na história peninsular que as invasões francesas provocaram bem como a marca profunda deixada na história portuguesa e na sua colónia brasileira. Os textos fazem-se acompanhar de uma cronologia dos factos ocorridos e de um aparato iconográfico da época que lembra protagonistas, mas também abordagens caricaturais e satíricas através da reprodução de gravuras que tomam grandemente por objeto Napoleão Bonaparte.

Ainda no mesmo mês de março, o Público dedica um artigo de duas páginas à epistolografia de William Warre, ajudante de campo do marechal Beresford e que em cartas dirigidas a seu pai dá testemunho das dificuldades e situações-limite vividas pelo Portugal de então ou, como se pode ler no jornal, Warre " [...] deixou-nos um pungente testemunho da crueldade das invasões francesas e da devastação que causaram em Portugal." (Carvalho, 2009: 9) Nos textos epistolares de Warre, destaca-se o testemunho sobre a destruição, a fome, a violência, a dureza da guerra e o reconhecimento da bravura dos portugueses, referindo mesmo a " [...] fúria deste povo apaixonado e desejoso de vingança." (Warre apud Carvalho)

O desastre da Ponte das Barcas será também objeto de atenção periodística ainda no mesmo $n^{\circ}$ do jornal de 2009, recordado como "O dia mais negro da história do Porto". Em texto de Luís Miguel Queirós, relembra-se, com preocupações de natureza histórica, a "fatídica manhã" de 29 de março de 1809 em que muitas centenas ou mesmo milhares de vítimas pereceram nas águas do Douro e lembra-se ainda que se o escultor Teixeira Lopes já tinha criado um baixo-relevo evocativo da tragédia, comummente apodado de "alminhas das pontes", agora será a vez de Souto Moura recordar o acontecimento com escultura comemorativa.

Mas já em setembro de 2007, o Diário de Notícias informava sobre as comemorações em preparação no Porto organizadas por Valente de Oliveira, acentuando que sobretudo a segunda invasão deixou memória mais perene. Afirma-se a necessidade de

\footnotetext{
${ }^{8} \mathrm{O}$ mesmo tipo de procedimento encontramo-lo em Espigueiro. Central de informações regionais (http://www.espigueiro.pt/reportagem/b56a18e0eacdf51aa2a5306b0f533204.html).
} 
vulgarização, pois é importante " [...] informar o cidadão comum do que foi, por exemplo, o desastre da ponte das Barcas." (Diário de Notícias, 27 setembro 2007)

Ontem e hoje

Ontem, "Um Monstro de ambição e de vingança/ Surge do centro do sulfúreo Averno/ Perde a Europa o equilíbrio da balança" (1809: 57), hoje, mais propriamente em 2003, o nome de Napoleão aparece em 5ำ lugar enquanto grande figura histórica que representou a identidade europeia (História 2005:35), numa sondagem que não contemplou Portugal. O que perdura ou o que há de novo na memória coletiva portuguesa?

Continuidade de representações nas presenças materiais de uma memória coletiva, memória que parece apenas precisar de ser reavivada com intuitos de vulgarização, não importando, na revisitação da história, lembrar um conjunto de prolongamentos ou de consequências ideológicas que esse contacto com os franceses poderá ter implementado. Importará apenas a memória pacificada do factual, vista no curto termo, ignorando o que possa ter sucedido na longue durée. De resto, tal pacificação revela-se já na adoção que o século XIX fez de um modelo cultural francês, mercê de uma situação cultural periférica vivida por Portugal face um funcionamento civilizacional da França visto como modelar, mercê ainda de elites culturais que pelo exílio conheceram e/ou estão disponíveis para acolher propostas estéticas e/ou ideológicas de matriz francesa. Assim, fala-se e lembra-se o que sucedeu em espaço peninsular, mas não se refere, por exemplo, a Legião Portuguesa que combateu ao serviço francês e que desse modo tomou contacto com novas propostas no que tocaria à administração de um Estado moderno. Parece não haver lugar para uma memória reflexiva, restando então o discurso da efeméride que no entanto serve uma revitalização no domínio da investigação nesta área de estudos e para a qual o presente colóquio contribui. 


\section{Bibliografia}

AA.VV. (2009). O Porto e as Invasões Francesas. 1809-2009. IV vols: Público/Câmara Municipal do Porto.

Abelha do Meio-Dia (1809). Lisboa: Na Impressão Régia.

ALMEIDA, Teresa Caillaux de (2007). "La mémoire des campagnes napoléoniennes au Portugal (1807-1811). Au croisement des sources orales, écrites et iconographiques », Actes du colloque Interdisciplinaire : nouvelles perspectives de la recherche française sur la culture portugaise, pp. 27-38 : http://www.msh-clermont.fr/IMG/pdf/04-CAILLAUX_27-38_br.pdf. [consultado em 29/0972010] BELLER, Manfred (2007). "Perception, image, imagology". The cultural construction and literary representation of national characters. A critical review. Beeler \& Leerssen (ed.). Amsterdam-New York, Rodopi.

« Bispo do Porto em Santo Tirso para Falar das Invasões Francesas ». In Santo Tirso Hoje http://www.santotirsohoje.com/?tag=invasoes-francesas. [consultado em 29/0972010] (2009). "Caldense é comissário de comemorações das Invasões Francesas em Pombal". Jornal das Caldas. Edição On-line,12 março http://www.jornaldascaldas.com/index.php/2009/03/12/caldense-e-comissario-decomemoracoes-das-invasoes-francesas-em-pombal/ [consultado em 29/0972010] CARDOSo, Manuel Fernando Vizela Marques (2010). "Portugal nas vésperas das invasões francesas; contexto geopolítico e geoestratégico", Revista Militar http://www.revistamilitar.pt/modules/articles/article.php?id=545.[consultado em 29/09/2010] CARDOso, Rui (2010). Invasões Francesas 200 anos. Mitos, histórias e protagonistas. Lisboa: Imprensa Nacional-Casa da Moeda.

(2009). “'Cartas da Península' reeditadas 100 anos depois”. In Público, 9 novembro http://www.publico.clix.pt/Cultura/cartas-da-peninsula-reeditadas-100-anos-depois_1409014. [consultado em 20/09/2010]

CARVALHO, Manuel (2009). "Pai, há crianças que vivem de urtigas que apanham nos campos”, Público, 29 março.

(2008). “Comemoração do Bicentenário das Invasões Francesas em Mesão Frio”. In: Espigueiro,6 de Junho http://www.espigueiro.pt/reportagem/b56a18e0eacdf51aa2a5306b0f533204.html. [consultado em 29/0972010].

CORREIA, Rita [2007]. "Invasões Francesas: o esgrimir das penas e os papéis incendiários"http://hemerotecadigital.cmlisboa.pt/Recursos/nformativos/EstudosInternos/Inva soes/ConfInvasoes_RC.pdf.Diário de Notícias, 2007. [consultado em 29/09/2010] 
(2009). "Duzentos anos das Invasões Francesas arrancam com exposição e conferência", In Semanário Transmontano, 16 janeiro

http://www.semanariotransmontano.com/noticia. $a s p ? i d E d i c a o=171 \& i d=7289 \& i d S e c c a 0=235$ 2\&Action=noticia [consultado em 22/09/2010].

J.L.C.M. (1809). Resumo Histórico dos Memoráveis Sucessos da Restauração do Porto, Lisboa: Tipografia Lacerdina.

MACHAdO, Álvaro Manuel e PAgEAuX, D.-H. (2001). Da Literatura Comparada à Teoria da Literatura. Lisboa: Editorial Presença.

MANGAS, Francisco (2007). "Porto evoca a tragédia das invasões francesas". In Diário de Notícias, 27 setembro

http://dn.sapo.pt/inicio/interior.aspx?content_id=985630http://dn.sapo.pt/inicio/interior.aspx?c ontent_id=985630 [consultado em 20/09/2010].

MATOS e LEMOS, Mário (2009), "Ecos da invasão do Porto na imprensa de Lisboa", O Porto e as Invasões Francesas1809-2009, vol. IV, Público/Câmara Municipal do Porto, pp.171-203. (1809) Observador Português, Histórico e Político de Lisboa, Lisboa: Na Impressão Régia. PAGEAUX, Daniel-Henri (2003). Trente Essais de Littérature Générale et Comparée ou la Corne d'Amalthée. Paris : L'Harmattan.

Público, [destacável], s.d, 2009.

(2009). "Porto evoca os 200 anos do desastre da Ponte das Barcas ocorrido durante as Invasões Francesas". In Público, 25 março http://www.publico.pt/Cultura/porto-evoca-os200-anos-do-desastre-da-ponte-das-barcas-ocorrido-durante-as-invasoesfrancesas_1370848 [consultado em 20/09/2010].

SARDICA, José Miguel (2004-2005). [dossier sobre Napoleão Bonaparte]. In História, ํo72, Dez./Jan. pp. 20-35.

TengarRinhA, José (1989). História da Imprensa Periódica Portuguesa. 2ª ed., Lisboa: Editorial Caminho. 